\title{
Stochastic Dynamic Programming with Markov Chains for Optimal Sustainable Control of the Forest Sector with Continuous Cover Forestry
}

\author{
P. Lohmander ${ }^{1, *}$ and S. Mohammadi Limaei ${ }^{2}$
}

\begin{abstract}
We present a stochastic dynamic programming approach with Markov chains for optimal control of the forest sector. The forest is managed via continuous cover forestry and the complete system is sustainable. Forest industry production, logistic solutions and harvest levels are optimized based on the sequentially revealed states of the markets. Adaptive full system optimization is necessary for consistent results. The stochastic dynamic programming problem of the complete forest industry sector is solved. The raw material stock levels and the product prices are state variables. In each state and at each stage, a quadratic programming profit maximization problem is solved, as a subproblem within the STDP algorithm.
\end{abstract}

Keywords: Optimization, Stochastic dynamic programming, Markov chains, Forest sector, Continuous cover forestry.

Manuscript was received on 31/05/2017 revised on 01/09/2017 and accepted for publication on 05/09/2017

\section{Introduction}

Here, we are to coordinate certaint activities in an optimal way in a typical forest industry sector in the presence of stochastic markets. The activities are: Pulp and paper production and sales, sawn wood production and sales, wood based energy production and sales, raw material procurement and sales, harvest operations, and logistic solutions.

For each year (or other period) and possible price and stock states, the profit is maximized using quadratic programming. The one year quadratic programming problems are considered as subproblems within a stochastic dynamic programming Markov chain master problem. The master problem which is maximizing the expected present value of the forest sector over an infinite horizon, can be solved via linear programming.

The forest sector includes several types of industrial plants, such as pulp mills, sawmills and wood based energy plants. The statistics clearly shows that such plants have paid very different prices for the raw materials from the forests. One illustration of this is found in Fig. 1. This variation in relative input prices is most likely based on large variations in the relative prices in the pulp and energy markets. In order to optimize the total profitability of the sector, it is necessary to sequentially take

\footnotetext{
* Corresponding Author.

1 Optimal Solutions in cooperation with Linnaeus University, Umea, Sweden, Email: peter@ lohmander.com. 2 Department of Forestry, Faculty of Natural Resources, University of Guilan, Sowmeh Sara, Iran, Email: limaei@guilan.ac.ir
} 
price changes into account, and to adapt production in an optimal way. The prices are not only difficult or impossible to predict perfectly, but are also affected by the volumes produced and sold in

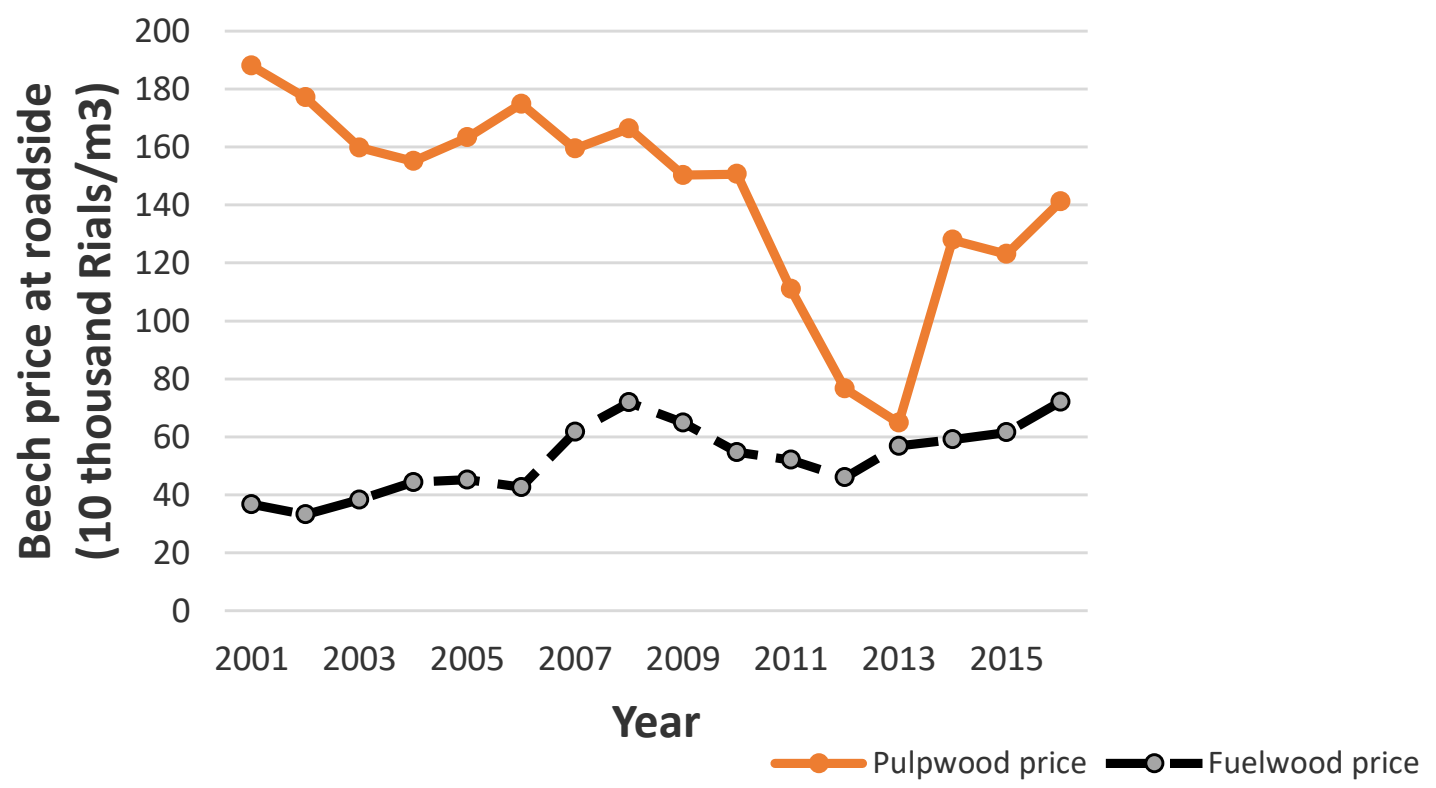

Figure 1. The inflation adjusted prices at roadside in Iranian Caspian forests for beech used for different purposes, namely pulpwood and fuelwood. The inflation adjustment has been made via CPI, the consumer price index. (The prices are shown at the price level of 2016.) Note that the relation between the pulpwood price and the firewood price has changed considerably over time. [1].

the markets. These production volumes are decision variables in the present maximization problem. In a particular year, we may approximate the prices as linear functions of the production volumes. With higher volumes, the prices fall. The cost function is assumed to be convex. The profit function becomes a strictly concave quadratic function of the production volumes. If we control the forest sector with several types of mills and products, we may also derive prices of particular products as linear multidimensional functions of the production volumes of several products. In typical cases, the product prices may be negatively affected by the production volumes of similar products. As a result, the approximation of the total profit function becomes a strictly concave quadratic multidimensional function of all production volumes. With linear constraints, representing wood resources, mill capacities and logistic constraints, we obtain a quadratic programming maximization problem. Such a problem can be solved with a standard software and the global maximum is obtained in a finite number of iterations. Note that in the problem model below, $x_{j}$ is the production volume of product $j$ and $\pi$ is the profit. $p_{j}$ and $r_{j t}$ are profit function parameters. $C_{i}$ is the capacity of resource $i$ and $\alpha_{i j}$ is the amount of that resource used per unit of product $j$ :

$$
\begin{aligned}
\max \pi\left(x_{1}, \ldots, x_{K}\right)= & p_{0}+p_{1} x_{1}+\ldots+p_{K} x_{K}+ \\
& +r_{11} x_{1}^{2}+r_{12} x_{1} x_{2}+\ldots+r_{1(K-1)} x_{1} x_{K-1}+r_{1 K} x_{1} x_{K}+ \\
& +\ldots \\
& +r_{K 1} x_{K} x_{1}+r_{K 2} x_{K} x_{2}+\ldots+r_{K(K-1)} x_{K} x_{K-1}+r_{K K} x_{K}{ }^{2}
\end{aligned}
$$


S.t.

$$
\left\{\begin{array}{c}
\alpha_{11} x_{1}+\ldots+\alpha_{1 K} x_{K} \leq C_{1} \\
\ldots \\
\alpha_{L 1} x_{1}+\ldots+\alpha_{L K} x_{K} \leq C_{L} .
\end{array}\right.
$$

The quadratic profit maximization problems should be solved any time new information concerning the stochastic market changes appear. It is quite possible to use hours, days, weeks or years as periods. In each period, the following problem should be solved:

$$
\begin{aligned}
& \max \pi\left(x_{1}, \ldots, x_{K} ; u, t, s, m\right) \\
& \text { s.t. } \\
& \alpha_{11}(u, t, s, m) x_{1}+\ldots+\alpha_{1 K}(u, t, s, m) x_{K} \leq C_{1}(u, t, s, m) \\
& \ldots \\
& \alpha_{L 1}(u, t, s, m) x_{1}+\ldots+\alpha_{L K}(u, t, s, m) x_{K} \leq C_{L}(u, t, s, m)
\end{aligned}
$$

Note that the parameters of the maximization problem are functions of the changing values of $(u, t, s, m)$. These variables represent control decisions exogenous to the quadratic profit maximization problem, time, the state of the forest resource and the state of the markets. The many quadratic profit maximization problems, one for each period, state of the forest and state of the markets, may be embedded within a stochastic dynamic programming problem of the following type:

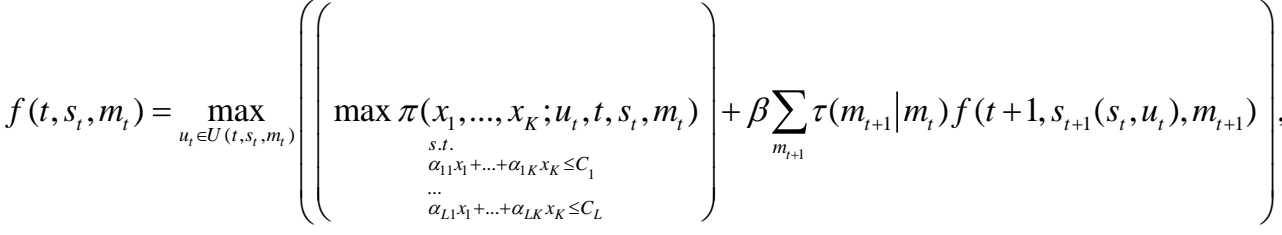

$$
\begin{aligned}
& \forall\left(t, s_{t}, m_{t}\right) \mid(0 \leq t \leq T),
\end{aligned}
$$

where $f\left(t, s_{t}, m_{t}\right)$ is the expected present value of the forest sector as a function of time, state of the forest and state of the markets, given that all future decisions are optimally taken, conditional on future information, $U($.$) is the set of feasible controls, controls that are exogenous to the period and$ state specific quadratic profit maximization problems, $\tau\left(m_{t+1} \mid m_{t}\right)$ is the market state transition probability, the probability that the markets move from state $m_{t}$ in period $t$ to state $m_{t+1}$ in the next period, $\beta$ denotes the one period discounting factor, and $T$ is the time horizon.

\section{Infinite Time, Markov Chains, Stationarity and Sustainability}

Sustainable systems are usually desired. We want the forests and the environment to last forever. Continuous cover forestry is easier to handle within the framework of dynamic programming than forestry with final harvests. Marginal harvest level changes more or less instantly affect the forest production level until the next period. With final harvests, the production is discontinuous and includes delays of many years between control and effects on the future wood flow.

Below, we make marginal changes of the problem, in order to make the exposition easier to follow. Let, $i_{t}$ denote "state" ( $i_{t}$ contains all of the information of $s_{t}$ and $m_{t}$ in the earlier part of this paper). Then, 


$$
\begin{aligned}
f^{*}\left(t, i_{t}\right)= & \max _{u_{t}}\left(\pi^{*}\left(u_{t} ; t, i_{t}\right)+\beta \sum_{i_{t+1}} \tau\left(i_{t+1} \mid t, i_{t}, u_{t}\right) f^{*}\left(t+1, i_{t+1}\right)\right), \\
& u_{t} \in U\left(t, i_{t}\right) .
\end{aligned}
$$

Now, we assume stationarity. Hence, $f(t, i)=f(i)$. We can determine the optimal values of $f(i)$, denoted by $f^{*}(i)=f_{i}^{*}$, as follows.

Note that

$$
f_{i} \geq \pi^{*}(u ; i)+\beta \sum_{j} \tau(j \mid i, u) f_{j}, \quad \forall i, u \mid u \in U(i)
$$

and

$$
f_{i}^{*}=\pi^{*}\left(u^{*} ; i\right)+\beta \sum_{j} \tau\left(j \mid i, u^{*}\right) f_{j}^{*}
$$

The optimal value is determined via the following linear programming problem:

$$
\begin{aligned}
& \min Z=\sum_{i} f_{i} \\
& \text { s.t. } f_{i}-\beta \sum_{j} \tau(j \mid i, u) f_{j} \geq \pi^{*}(u ; i), \quad \forall i,\left.u\right|_{u \in U(i)} .
\end{aligned}
$$

The optimal decisions, $u_{i}^{*}$, are those values of $u_{i}$ that make the constraints binding. In other words, the constrains with zero slacks indicate the optimal decisions.

\section{General Properties of the Solutions}

Of course, optimal numerical results are functions of the particular parameter values used. The estimation of these parameter values is an empirical problem and has been ignored in this theoretical and general analysis. Related models have however been studied in the past. Some of the general conclusions derived from earlier numerically specified versions of similar models are the followings.

When the future prices of the final products are stochastic: "The expected present value of the profit is higher when the suggested method is used instead of a deterministic linear programming. The expected dual variables (shadow prices) associated with the industrial capacity restrictions are underestimated via deterministic multi period linear programming. Industrial flexibility is valuable and the optimal levels of maximum production capacities are higher than those in a deterministic world." These results were reported by Lohmander [2]. 
More problem specific results may be obtained in several cases. Such results are reported in Lohmander [3], [4], [5], [6], [7], Lohmander and Mohammadi [8] and Olsson and Lohmander [9].

\section{Conclusions}

A general framework for forest sector optimization was presented. Several examples of related studies and particular results were reported. Considerable economic gains should be expected if the suggested method replaced the traditional stiff long term planning methods. Furthermore, the forest is managed via continuous cover forestry, which leads to environmental advantages as compared to forest management with clear fellings. The complete system is adaptive and sustainable.

\section{Acknowledgments}

The first author greatly appreciates travel grants from FORMAS.

\section{References}

[1] Forests, rangelands and watershed management organization of Iran, Pulpwood price and the firewood price, http://www.frw.org.ir/00/En/default.aspx, 2016.

[2] Lohmander, P. (1989), Stochastic dynamic programming with a linear programming subroutine: Application to adaptive planning and coordination in the forest industry enterprise. In: Lohmander P. (Ed), Scandinavian forest economics, No. 31, 51p.

[3] Lohmander, P., Optimal stock and purchase policy with stochastic external deliveries in different markets, $12^{\text {th }}$ Symposium for systems analysis in forest resources, Vermont, USA, http://www.lohmander.com/Vermont2.ppt, September 2006.

[4] Lohmander, P., Stochastic dynamic optimization of forest industry company management, INFORMS International, Puerto Rico, http://www.Lohmander.com/SDO.ppt, 2007.

[5] Lohmander, P. (2007), Adaptive optimization of forest management in a stochastic world. In: Weintraub A. et al. (Ed), Handbook of operations research in natural resources, Springer science, International series in operations research and management science: New York, 525-544.

[6] Lohmander, P., Optimal adaptive stochastic control of large scale energy production under the influence of market risk, Keynote, 9th International conference of the Iranian Operations research Society, IORC 2016, Shiraz university of technology, Iran, http://www.Lohmander.com/PL_Shiraz_KEYNOTE_16.pdf and http://www.Lohmander.com/PL_Shiraz_KEYNOTE_Paper_16.pdf, April 2016.

[7] Lohmander, P. (2018), Applications and Mathematical Modeling in Operations Research, In: Cao B.Y. (Ed), Fuzzy Information and Engineering and Decision. IWDS 2016. Advances in Intelligent Systems and Computing, Vol 646. Springer, Cham, 46-53.

[8] Lohmander, P., and Mohammadi Limaei, S. (2008), Optimal continuous cover forest management in an uneven-aged forest in the north of Iran, Journal of Applied Sciences, 8(11), 1995-2007. 
[9] Olsson, L., and Lohmander, P. (2005), Optimal forest transportation with respect to road investments, Forest Policy and Economics, 7(3), 369-379. 